\title{
Explaining Regulatory Non-compliance: A Survey Study of Rule Transgression for Two Dutch Instrumental Laws, Applying the Randomized Response Method ${ }^{1}$
}

\author{
Henk Elffers, ${ }^{2,5}$ Peter van der Heijden, ${ }^{3}$ and Merlijn Hezemans ${ }^{4}$ \\ Within a rational choice framework, secondary data analysis of a survey study on \\ compliance with two Dutch regulatory laws is carried out. Selection of \\ explanatory variables to be considered is guided by a heuristic device, called \\ the "Table-of-Eleven." Using adapted logistic regression analysis, we show that \\ self-reported compliance, measured by means of a randomized response \\ procedure, can be explained in terms of benefits of non-compliance, social \\ norms and deterrence, while knowledge and general norm-conformity have no \\ role to play. The impact of various contributing factors turns out to be rather \\ different in size for the two laws.
}

KEY WORDS: regulatory non-compliance, randomized response, table-ofeleven, rational choice.

\section{INTRODUCTION}

Modern western society is riddled with laws. What lay people usually associate with the idea of law is crime and punishment, embodied in penal law. There is, however, a rather more voluminous set of rules and sanctions ordering and governing public life. These laws are aimed at ordering and

\footnotetext{
${ }^{1}$ Part of the work of the first and last author was done when they were affiliated with the Faculty of Law, Erasmus University Rotterdam.

${ }^{2}$ Netherlands Institute for the Study of Crime and Law Enforcement, NSCR, Leiden, The Netherlands.

${ }^{3}$ Department of Methodology and Statistics, Faculty of Social Sciences, University of Utrecht, Utrecht, The Netherlands.

${ }^{4}$ De Nederlandsche Bank $D N B$, Amsterdam, The Netherlands. (The views expressed here do not necessarily reflect those of DNB).

${ }^{5}$ To whom correspondence should be addressed at NSCR, P.O Box 792, 2300 AT Leiden, The Netherlands. E-mail: Elffers@nscr.nl.
} 
maintaining the economic life, prescribing certain ways of behaving, and proscribing others. In many cases the government gives permission to engage in a certain branch of economic activity, but under strict conditions. Such laws, sometimes called instrumental laws or regulatory laws, often threaten those who do not comply with punishment - in the form of fines or the retraction of permits - either by declaring transgression of the rules criminal under the penal code, or by incorporating punitive measures in the regulatory law itself.

Non-compliance with any law may be of two types: errors, whether due to lack of knowledge or concern, and deliberate or wilful non-compliance. If the law threatens sanctions for non-compliance, these are usually harsher for wilful non-compliance than for error; indeed errors may only need to be rectified without the application of sanctions.

While behavior under criminal law has been the criminologist's domain for a long time, behavior under regulatory law has been far less studied. Makkai and Braithwaite's classic article on the relation between criminology and research in regulatory compliance is ten years old (Makkai and Braithwaite, 1991), but Parker's influential review study (OECD, 1999) shows that, despite methodological proposals, there have been few empirical studies since. An exception may be made for the study of fiscal compliance, using methods of empirical social psychology, although most empirical work is already from the eighties (Roth and Scholz, 1989; Elffers, 1991; Slemrod, 1992; a recent review is given by Andreoni et al., 1998). Empirical work on regulatory compliance can also be found within the tradition of law and economics (e.g., Hatcher et al., 2000; Heyes, 2000), while traffic violations have been studied rather extensively (e.g., Parker et al., 1992).

We will concentrate in this paper on non-compliance with regulatory laws by individual citizens, distinguishing it from rule transgressing by members of an organization, which is the field of white collar or corporate crime. Corporate and organizational crime theory considers crimes - usually with an economic flavor - performed by individuals within an organizational context, and motivated or enhanced by this organizational context. Many authors have observed that individual behavior within or without an organizational context may widely differ (e.g., Vaughan, 1998). In the present article we will concentrate on transgression of regulatory rules by individuals. The examples we will treat are cases where no organizational behavior is involved.

Empirical research on individuals' regulatory compliance has been rather scarce. Part of the explanation is a lack of statistics on regulatory non-compliance. In the case of the enforcement of penal law, it is the job of the police and justice authorities to compile and publish statistical data on crime and enforcement. In the case of regulatory law enforcement, the 
situation is different. Enforcement is not entrusted to the regular police, but to special departments ("special enforcement units", "inspectorates"), often only installed by virtue of the law they have to enforce. These departments are often rather small for the task they face, necessarily concentrating on administration rather than enforcement. Documenting their enforcement activities and observed compliance is thus not their first priority. Moreover, the quality of non-compliance statistics is often dubious. In many cases it is the duty of the government department administering that law to check the declarations of the people operating under the law, but that control is often no more than superficial.

Apart from using the official statistics of enforcement agencies, the study of non-compliance can be approached by means of surveys, asking a sample of people operating under the relevant regulatory law to report on their own behavior. It is of course difficult to establish whether people actually do or do not comply on the basis of self-reports (see e.g., JungerTas and Haen Marshall, 1999; and in a regulatory context, Hessing et al., 1988). Reporting non-compliance is by no means neutral behavior, and studies are therefore vulnerable to misrepresentation out of either social desirability or self-presentational motives, or lack of awareness. In this study we use the randomized response method (RR) to circumvent these problems in measuring non-compliance behavior in a survey context.

In addition to satisfactory operationalization of the dependent behavior, any attempt to explain non-compliance demands an economicpsychological model for how people or organizations decide to comply or not to comply. In this paper we will make use of the Table-of-Eleven $\left(\mathrm{T}^{11}\right)$, which is a Fishbein-Azjen-style explanatory model that explains behavior in attitudinal cost-benefit terms. It has been developed especially for use in the regulatory compliance context.

We report here on two parallel survey studies on regulatory noncompliance under two laws in the Netherlands, viz. the law on individual rent subsidy (LRS) and the law on agricultural chemicals (LAC).

\subsection{Law on Individual Rent Subsidy LRS}

The LRS works as follows. The Dutch government sees it as its duty to enhance housing for the Dutch populace. In order to enable those of slender means to live in a decent dwelling, the individual rent subsidy law LRS states that a family can apply for an individual rent subsidy as soon as the rent of their house exceeds a certain fraction of their taxable income, provided that the latter does not exceed a certain threshold. The amount of rent subsidy is a rather complicated function of - among other thingshousehold taxable income, household composition and rent due. Some 1.0 
million households (out of a total of 6.6 million households) in Holland receive individual rent subsidy, more than half of which are single person households. The average amount they obtain is $108 €$ per month per household, the total amount runs to over 1.3 milliard $€$, or $0.4 \%$ of GDP (figures over the year 1997, from Statistics Netherlands, 2000). The law is rather complex, and requires from those who apply full disclosure of their taxable income, family situation, housing situation and so on. For applicants and beneficiaries of the LRS, failure to report all relevant information to the LRS-authorities is punishable by a discount or cancellation of the subsidy, with administrative fines proportional to the amount defrauded, while serious cases may also be sent to the public prosecutor for criminal proceedings. However, in the daily practice of the LRS, revealed non-compliance is being dealt with administratively only: people have to pay back the incorrectly received subsidy and face an administrative fine.

Defrauding the LRS can be attempted in several ways. One of them is by understating taxable income, an other one is by wrongly stating that one has a single household, while indeed forming a couple or living together with children or other people having an income as well, and cashing a too high subsidy based on this incorrect information. Defrauding the LRS is an act of individual persons, or heads of households, so non-compliance is an individual decision, without an organizational context. Though LRS fraud is a financial crime, it should not be seen as white collar crime in the traditional sense of the word. Income levels of LRS applicants are at the very low side of the income distribution.

The LRS authorities routinely carry out full administrative checks on all data supplied by LRS applicants, for completeness and internal consistency, and by comparing income figures with data from the tax department. Moreover, a special fraud squad occasionally investigates beneficiaries' housing and income situation "on the spot".

\subsection{Law on Agricultural Chemicals LAC}

The second law, the LAC, should be understood in the following context. Farmers use agricultural chemicals on their crops to suppress weeds and fight parasites and insects. The chemicals used are of course to some extent poisonous. For reasons of public health and environmental protection, the law on agricultural chemicals specifies which chemicals are allowed for which crops, which are forbidden, and stipulates the conditions on how to store and use these chemicals, and how to clean up after usage. Non-compliance with this law by farmers can take the form of using forbidden chemicals (sometimes allowed and easily purchased in foreign 
countries), or by applying them incorrectly, e.g., at the wrong time or on the wrong type of crop. There is a clear incentive to use some forbidden chemicals, as farmers believe them to be more effective, cheaper or easier to apply than those allowed. They may also be tempted, for reasons of costs or labor, to by-pass the prescribed rules for storing dangerous chemicals.

The "Algemene Inspectie Dienst AID" (General Inspection Unit of the Ministry of Agriculture) is in charge of controlling and enforcing the law, and does so by occasionally visiting farms, inspecting the premises, and investigating the farmer's books. Each year, some $10 \%$ of all farms are visited. When proscribed behavior is uncovered, the farmer is liable to a fine or to criminal prosecution. The fines issued by the AID are considered to be rather stiff. Criminal prosecution is an exception.

Though in a strict sense the LAC is addressing corporations (farming businesses), in practice all decisions on non-compliance are taken by individual farmers. Dutch farming is to an overwhelming extent a business of single proprietors/family business, and large scale farming corporations are almost absent. Almost $90 \%$ of all labor on Dutch farms is provided by the owner and his family (Statistics Netherlands, 2000). So, we consider LAC non-compliance as outside the province of the organizational crime approach.

\subsection{Outline of the Article}

We present a secondary analysis of data relating to compliance already gathered and reported in a project of the Expertisecentrum Rechtshandhaving ERH (Expert Centre for Law Enforcement) of the Dutch Ministry of Justice. The latter study uses not only survey data, but also interviews with enforcement officers of the laws concerned. A full report, in Dutch, is published as Monitorrapport (1998) ${ }^{6}$. From this study, we reanalyze data on the LRS and the LAC, two very different laws, providing examples of the problems outlined above. Observing transgression of these laws is by no means easy. They do provide, however, an excellent opportunity for looking into the feasibility and power of the $\mathrm{T}^{11}$ model and the RR-method.

We present successively a discussion of the theoretical background and of the Table-of-Eleven, the instrument with which we will explain noncompliance (\$2); measurement of non-compliance (\$3); design of the LRS and the LAC studies (§4); results (§5); discussion (\$6).

\footnotetext{
${ }^{6} \mathrm{We}$ are grateful to the Expertisecentrum Rechtshandhaving ERH (Expert Centre for Law Enforcement) of the Dutch Ministry of Justice for providing access to the data.
} 


\section{EXPLAINING NON-COMPLIANCE}

\subsection{Rational Choice Theory of Non-compliance}

Why do people transgress a law? We propose working within a rational choice framework, for which the classic reference is Becker (1968). This approach starts from the assumption that people who have to choose between various alternatives evaluate the expected outcomes of the alternatives, and choose the one promising the best outcome. In a lawbreaking context, this means that a would-be perpetrator tries to value what will result in the best net result: complying with the rule or transgressing it. He simply chooses the latter if it has a higher expected value than the former. As a thought model, the Beckerian assumption is pretty clear, but any empirical application of the model raises the question of what we (or at least the would-be perpetrators) should or would take into account into the valuation function. Of course, the net monetary outcome is part of this evaluation (results of transgressing minus costs incurred for transgressing). In the LRS-example this would mean that a beneficiary considers what he would gain from under-reporting taxable income (more rent subsidy), but corrects for expected costs (such as expected fines: fine times probability of being caught). In the LAC-example the net result would perhaps be: expected surplus market price of healthy crop minus costs of buying and applying proscribed chemicals minus expected fines. However, such direct monetary rewards of non-compliance are by no means necessarily the only imaginable part of the evaluation.

Theoretically, non-monetary costs could also be included, such as the disadvantages of rule transgression in terms of social disapproval, guilt, or damage to image. The classical reference here is Fishbein and Ajzen (1975), who hold that almost all of this type of influence can be subsumed under the headings of attitudes with respect to, and social norms about, the relevant behavior. Combining monetary and non-monetary costs, and individuals' perceptibility to both, into a rational choice theory of criminal decision making has been discussed for individuals' behavior by many authors, e.g., Klepper and Nagin (1989), Casey and Scholz (1991), Nagin and Paternoster (1993), Elffers (1999), all in a tax context, and by e.g., Grasmick and Bursik (1990) and Elffers and Hessing (2001) in a general context. Paternoster and Simpson (1996) discuss it in a corporate crime context. The main problem, though, is to decide which of these elements should be incorporated in the calculation of non-monetary costs, and how it should be done.

On the monetary side it is also not too clear exactly what should enter the evaluation. Should weight be given to the likelihood that non-compliance will result in a tighter control next year, costing more, or in a lower standing in the market among competitors, resulting in lower prices? It is arguable that these 
elements should be included, but if so, how should that be done? In theory, a weighted sum of "all" contributions is what is needed, but this requires a common scale of evaluation. Economists, for example, use the term "utility" to refer to this common but unknown yardstick, but without bothering too much how to measure utility. In the context of drunk-driving, Nagin and Pogarsky (2001) have proposed an ingenious scenario method of evaluating both legal and extra-legal consequences on a common money-based scale, as a first approach to such a generalized Beckerian yardstick in the field of regulatory non-compliance.

A more modest undertaking would be merely to list those elements that should enter into the valuation function, and to determine what elements indicate a significant advantage in non-compliance, and those which tend to make compliance the more advantageous option. We do not claim to know how to combine all these separate elements into one definite valuation function.

On the other hand, once we have a good measure of actual compliance, we can try to identify those elements in the evaluation function that do indeed correlate with compliance behavior, suggesting those that may help to explain compliance.

\subsection{The Table-of-Eleven $T^{11}$}

It is in the more modest task of cataloguing those factors that promote or oppose compliance that the Table-of-Eleven $\left(\mathrm{T}^{11}\right)$ approach can be useful. The $\mathrm{T}^{11}$ tries to list systematically the elements that form part of a valuation function for comparing the compliance and non-compliance options. It is a systematic way of looking at what aspects instigate non-compliance, and what aspects constrain the choice for non-compliance. Elements well-known in Fishbein-Azjen type attitude/norm theories about rule breaking enter $\mathrm{T}^{11}$, and the contribution of $\mathrm{T}^{11}$ is its systematising and its way of presenting the results. $\mathrm{T}^{11}$ has been developed by Ruimschotel and a number of co-workers (De eerste stap, 1994; Ruimschotel, et al. 1995; Ruimschotel, et al. 1996; Elffers and Ruimschotel, 1997; Van Reenen, 2000) and has been applied in the Netherlands in research projects of varying depth into compliance profiles of, among others, Precursorenwet (law on chemical substances), Bouwstoffenbesluit (law on re-use of refuse in the building industry), Taxiwet (taxi-driving law), Warenwet (retail law), Wet Wit- en Bruingoed (law on consumer durables), vulnerability to crime of the Rotterdam harbour, insurance fraud and social benefit fraud.

It should be understood that $\mathrm{T}^{11}$ is not a ready-made instrument, like a standard psychological test. Rather, it should be seen as a conceptual scheme that should be adapted to the problem at hand. It can be used for surveys, expert interviews and round tables, ex ante evaluation of laws, and 
so on. Nor is $\mathrm{T}^{11}$ a completely standardized instrument, but a complex of ideas used to address compliance inventories. In no two cases of $\mathrm{T}^{11}$ application to date has the $\mathrm{T}^{11}$ been the same. In most cases various elements were elaborated and others were played down or omitted. For some applications, software has by now been developed for facilitating the on-line gathering and analyzing of $\mathrm{T}^{11}$ data. We use $\mathrm{T}^{11}$ here as a thought ordering scheme. ${ }^{7}$

\subsection{The Dimensions of the $T^{11}$}

The $T^{11}$ enumerates eleven dimensions, $T_{1}$ to $T_{11}$, subdivided in two broad classes. The first class, consisting of the factors $T_{1}$ to $T_{6}$, consists of those factors that are not under direct control of a control agency. They are called spontaneous compliance factors. The second set of factors, $\mathrm{T}_{7}$ to $\mathrm{T}_{11}$, focus on the activities of the law-enforcing agency, and are called induced compliance factors. As indicated above, the term "factor" is used in a rather loose way, indicating a complex of influences that work in on the tendency to comply or not.

Among the spontaneous factors we distinguish:

$\mathrm{T}_{1}$ : The lack of KNOWLEDGE ABOUT AND CLARITY OF RULES is seen as a factor promoting non-compliance. Lack of knowledge and clarity can result in non-compliance by error, complexity can lead to disappearance of any will to obey the rules. Complexity also provides opportunities to disguise non-compliance as honest compliance.

$\mathrm{T}_{2}$ : COSTS AND BENEFITS associated with compliance and non-compliance are, in the true rational choice tradition, seen as important factors that can either promote or constrain non-compliance. Benefits of noncompliance is certainly the reason most often mentioned for explaining non-compliance. But it should be stressed that other costs and benefit elements can come in as well. Sometimes a would-be non-complier has to take the cost of non-compliance into consideration as well, which can have a restraining influence. Compliance too may have its costs and benefits.

$\mathrm{T}_{3}$ : ACCEPTABILITY of specific rules. It is easier to comply with rules if they are seen as reasonable, than if they are found unacceptable.

$\mathrm{T}_{4}$ : General NORM CONFORMITY with respect to laws and authorities can play a mitigating or restraining role, in the sense that such conformity may be able to neutralize any tendency to non-compliance.

${ }^{7}$ The rather loose meaning of the $\mathrm{T}^{11}$ paradigm implies that not necessarily all of its founding fathers will agree with the description below of what the first author of this article sees as the kernel of $\mathrm{T}^{11}$ methodology, cf. Elffers (2000). 
$\mathrm{T}_{5}$ : INFORMAL CONTROL by social environment ("SOCIAL NORM") is an important factor. What would friends and neighbors, or people under the same rule, say or think about non-compliance? Is non-compliance evident to them? Would they endorse or criticize non-compliance? Would they report it to the enforcing authorities?

$\mathrm{T}_{6}$ : Even if there are no official controls, non-compliance may come to the notice of the enforcers, either by chance, or through the carelessness of the transgressor. The higher the probability of SPONTANEOUS DETECTION, the less the tendency not to comply.

Analyzing the control process exercised by the enforcing agency, we can distinguish the following induced compliance factors:

$\mathrm{T}_{7}$ : CONTROL DENSITY, i.e., the probability that an arbitrary case will be controlled by the enforcing office. A higher control density should, ceteris paribus, reduce non-compliance.

$\mathrm{T}_{8}$ : CONTROL DEPTH, i.e., the conditional probability of detecting noncompliance given that a non-compliant case is checked.

T9: TARGETING of control activities, i.e., the ability of an enforcing agency to direct its control activities where deserved, rather than executing random checks.

$\mathrm{T}_{10}$ : SANCTION CERTAINTY is the conditional probability that a case will be prosecuted and lead to appropriate sanction, once non-compliance has been detected by the agency.

$\mathrm{T}_{11}$ : SANCTION SEVERITY is the degree to which a convicted non-complier suffers under the sanction, either because of the sanction itself (fine, confiscation, end of prerogatives, ...) or because of the damage to reputation.

\subsection{Expanding and Condensing $\mathrm{T}^{11}$}

It is the claim of the $T^{11}$ theory that the above eleven dimensions span the whole range of promoters and constraints that explain non-compliance. In terms of the Beckerian general evaluation function, it is claimed that this function depends on these eleven characteristics alone, although we do not know the exact form of that function. This claim looks more comprehensive than it actually is, as all dimensions are in fact labels for rather broad areas themselves, and in most applications of $\mathrm{T}^{11}$ one or more of the concepts are operationalized in several ways. For instance, the cost/benefit factor $\mathrm{T}_{2}$ may get a fourfold indication: $\mathrm{T}_{2 \mathrm{a}}$ : costs of compliance, i.e., the work or costs associated with complying with the rules, such as administrative burden; $\mathrm{T}_{2 \mathrm{~b}}$ : costs of non-compliance (sometimes called the "threshold of trespassing"); $\mathrm{T}_{2 \mathrm{c}}$ : benefits of non-compliance; $\mathrm{T}_{2 \mathrm{~d}}$ : benefits of compliance. All four 
will not always be needed, and executing a $\mathrm{T}^{11}$ study begins by making a wise choice of what (sub-)dimensions should be incorporated. For instance, when investigating money-laundering regulation compliance at financial institutions, it is clear that the costs of compliance are important, as compliance entails, among other things, that a firm should employ a number of compliance officers. But offending entails no costs, as it would merely involve no procedures being implemented. In this case $T_{2 b}$ is not relevant. Another example of a dimension often being subdivided is $T_{11}$, where sanctions are split into two parts: actual monetary fines, and the severity of damage done to peoples' good reputation. Sometimes a whole dimension need not be incorporated in a $\mathrm{T}^{11}$ study, as it clearly has no relevance to the rule at hand, e.g., $T_{8}$ is irrelevant when researching into the obligation to carry a light on a bicycle at night. If a police officer checks a bike, he is sure to see whether a light is present or not.

A $\mathrm{T}^{11}$ study consists of an operationalization of each (sub-)dimension, either rapidly and informally (e.g., a statement to which the respondent can assent or not, e.g., on a Likert 5-point scale), or alternatively in an elaborate way, using many questions for each dimension, constructing scales from them and so on. In the present paper, we concentrate on how $\mathrm{T}^{11}$ scores for individual respondents can explain non-compliance scores, by means of a logistic regression analysis.

A claim that compliance to any rule can be described in terms of the $\mathrm{T}^{11}$ does not imply that all dimensions make a separate contribution. In general, dimensions will be correlated for a given rule, over a group of respondents. Thus, in any concrete example of a rule, it may be possible to subsume several $\mathrm{T}^{11}$-dimensions because they are strongly related. This can be done on the basis of a scale analysis or factor analysis, or on an a priori basis, if we assume certain dimensions of the $\mathrm{T}^{11}$ to be highly associated in a given application. We call this procedure condensing $\mathrm{T}^{11}$. In some cases, we first expand the $\mathrm{T}^{11}$ into a number of sub-dimensions, as indicated above, to increase the validity, and then regroup them to increase the reliability, but this regrouping only occurs when the sub-dimensions are highly correlated. As an example, the various cost and benefit sub-dimensions, $\left(\mathrm{T}_{2 \mathrm{a}}, \mathrm{T}_{2 \mathrm{~b}}, \mathrm{~T}_{2 \mathrm{c}}, \mathrm{T}_{2 \mathrm{~d}}\right)$, are often taken together again, and sometimes control and sanction dimensions (such as $\mathrm{T}_{6}$ to $\mathrm{T}_{11}$ ) are strongly related in respondents' perception. A condensed $\mathrm{T}^{11}$ provides in many cases a more parsimonious as well as a more reliable measurement.

\section{METHODS FOR MEASURING NON-COMPLIANCE}

In order to be able to investigate whether and what dimensions of $\mathrm{T}^{11}$ explain the level of non-compliance, we should be able to relate $\mathrm{T}^{11}$-scores to 
non-compliance. Obviously, such an undertaking requires a good measurement instrument for non-compliance.

The surveys we are reanalysing here address the topic of the respondents' own non-compliance. Of course, directly questioning people about proscribed behavior is complicated by issues of social desirability, self-presentational concern, lack of awareness (Hessing et al., 1988; JungerTas and Haen Marshall, 1999). Two methods were used in this research: the locked box method and the randomized response method.

\subsection{The "Locked Box" Method}

The direct self-report used has been designed by the locked-boxtechnique (McCrohan, 1982) in which the respondent gets a number of cards, on each of which is printed one type of behavior, of different degrees of illegality, such as red light jumping, tax evasion, and of course also the one of interest here, non-compliance with the relevant law (LAC and LRS respectively). The respondent puts those cards describing behavior that he has engaged in himself in one of two boxes, the cards listing behavior he had not engaged in into the other box. The interviewer cannot see which cards are put into which box. Only afterwards does the research agency match the boxes with the respondent, on the basis of identification number.

\subsection{Randomized Response Method}

The randomized response method (Warner, 1965; Fox and Tracey, 1986) avoids asking a respondent to report his compliance behavior outright. The randomized response method can be designed in many ways. Here the so-called "unrelated question design" was used. Two questions were offered to the respondent, and a randomizing device, in this case a die. The respondent throws the die, unseen by the interviewer, and depending on the outcome the respondent is asked to answer one of the two questions. The trick is that one of these questions is an innocent one, the so-called "unrelated question", such as "Is your mother's birthday between January 1st and June 30th?", while the other is the "real question", in our case: "Did you transgress such-or-such rule in a given period of time?" When the die gives 1 or 2 , the respondent is supposed to answer the first question, when it is 3 to 6 , the second one. Because the interviewer is not allowed to see how the die falls, it should be understood that even if a respondent says "yes", the interviewer cannot infer that the interviewee admits non-compliance: he simply may have reported that his mother's birthday is in the first half of the year. It is believed that this device, when suitably explained to the respondents, enhances the quality of answers (Fox and Tracey, 1986; Chaudhuri and Mukerjee, 1988). 
For a critical evaluation of the method, see Umesh and Patterson (1991). A recent validation study (Van der Heijden et al., 2000) compared two versions of randomized response with computer-assisted self-interview and with face-to-face direct questioning. Individuals caught for fraud in welfare and unemployment benefit were shown to be most willing to admit non-compliance when questioned using either of the two randomized response methods. Complexity of the randomized response set-up is often seen as a matter of concern. However, Van der Heijden et al. (2000) researched a population with a rather low educational level $(70 \%$ has only lower vocational training or less), and nevertheless in $90 \%$ of the cases, cooperation during the interviews was evaluated by the interviewers as good or very good, although about $20 \%$ of the interviewees found it difficult to understand the randomized response procedures. Landsheer et al. (1999) show that admitting sensitive behavior using randomized response questions is significantly related to understanding the method, but not significantly related are trust in the interviewers, reading/writing skill and educational level. Lensvelt et al. (2002) perform a meta-analysis, summarizing all studies in which randomized response is compared with other data collection methods. They find that randomized response not only produces better population estimates than direct questioning, self-administered questionnaires and computer-assisted methods, but also that with increasing sensitivity of the topic the benefits of using randomized response increase.

The probability of non-compliance can be estimated as follows. Let $p(y e s)$ be the probability of a "yes"-answer. This probability is composed of the probability to answer "yes" to the unrelated question ("is your mother's birthday between January 1 and June 30?") and the probability of answering "yes" to the non-compliance question. Let $p$ (yes|unrelated) be the probability of answering "yes" given that the respondent has to answer the unrelated question, and let $p$ (yes|non-com) be the probability to answer "yes" to the non-compliance question, i.e., the parameter of interest. In our set-up, the probability that someone has to answer the unrelated question is $1 / 3$, while, given the unrelated question in our case, $p($ yes $\mid$ unrelated $)=1 / 2$. Then

so that

$$
\begin{aligned}
p(\text { yes }) & =p(\text { yes } \mid \text { unrelated }) \times p(\text { unrelated })+p(\text { yes } \mid \text { non-com }) \\
& \times p(\text { non-com })=1 / 2 \times 1 / 3+p(\text { yes } \mid \text { non-com }) \times 2 / 3
\end{aligned}
$$

$$
p(\text { yes } \mid \text { non-com })=3 / 2 \times p(\text { yes })-1 / 4
$$

If we substitute the sample estimate of $p$ (yes), i.e., the fraction of people in the sample that answered "yes", then Eq. (1) yields an estimate of the probability of non-compliance. 
Incorrectly, some researchers seem to believe that the randomized response method has as a drawback that it would be impossible to investigate the relation between the randomized response variable (noncompliance) and explanatory variables such as the subscales of $\mathrm{T}^{11}$, because we do not know whether any individual case is admitting non-compliance or not. However, Fox and Tracy (1986) and Chaudhuri and Mukerjee (1988) discuss the analysis of randomized response data in cross tabulations extensively, and versions of logistic regression have been developed that are adjusted to cope with randomized response variables (Maddala, 1983; Scheers and Dayton, 1988; Van der Heijden et al., 2000).

Let $x(i)$ be the vector of explanatory variables for respondent $i$, and let $b$ be the vector of unstandardised regression weights, and let $c$ be the intercept. We can write the standard form of logistic regression as

$$
p(y e s \mid x(i))=\{\exp (b x(i)+c)\} /\{1+\exp (b x(i)+c)\}
$$

In the adjusted form of logistic regression we impute, following Eq. (1),

$$
p(y e s \mid x(i))=1 / 6+2 / 3 p(\text { yes } \mid \text { non-com, } x(i))
$$

and in this way the $b$-values can be interpreted in terms of $p(y e s \mid$ non-com, $x(i))$.

Because of the error induced by the randomized response procedure, the likelihood function for the adjusted logistic regression is less peaked. This can lead to numerical instabilities. In particular, when the number of explanatory variables in the regression is large, the algorithm for numerical maximization of the likelihood sometimes fails to converge. More details of the adjusted logistic regression procedure and the algorithm used can be found in the literature mentioned earlier.

Because it is rather difficult to interpret the resulting $b$-values from a logistic regression procedure directly, we propose to facilitate the interpretation as follows. First we check whether regression parameter estimates depart significantly from zero. Then, for those parameters satisfying that condition, we calculate the estimates of $p(y e s \mid x(i))$ for two strategically chosen $x(i)$ values, namely $x(i)$ being equal to plus or minus one standard deviation from the mean of $x$. We call the difference between those two estimated probabilities the effect size of regressor $x$.

\section{DATA}

In this article we present a secondary analysis of data gathered in a study (Monitorrapport, 1998) on monitoring regulatory law. The relevant parts here are two surveys, dealing with the law on agricultural chemicals (LAC) and the law on individual rent subsidy (LRS) as described above. 
The survey for the LAC was held by means of face-to-face interviews with owners of farms (in most cases family farmers, as indicated above) and small firms active in applying agricultural chemicals. All of them were personally involved in applying agricultural chemicals as regulated by the LAC. It was conducted in October 1996 with a sample of firms provided by the Ministry of Agriculture. The response was $45 \%$, amounting to 349 firms. The other survey, on the LRS, was held by means of face-to-face interviews in June and July 1996, among a sample of people having received individual rent subsidy in the previous year, provided by the Ministry of Housing. The response was almost $50 \%, 323$ persons in total. Response figures around $50 \%$ are, alas, rather common in Holland. Response was not selective in terms of background characteristics of the sample approached (for details we refer to Monitorrapport, 1998). The questions dealt with in this article were all read aloud to the respondent, who could indicate an answer on an answer card.

The questionnaires for both laws to be evaluated consisted of a number of items indicating the respondent's perception of $\mathrm{T}^{11}$ dimensions for that law, 27 items in total. Most items were 5 point, bipolarly labeled Likert items, like: "How much do you know about the rules concerning the level of the household income and the right on individual rent subsidy?", with scores 1-5, ranging from "very little" to "very much". Some questions required the respondent to estimate a percentage, as in "Assume that you would like to file an incorrect declaration about the height of your income, how big is the chance that your friends, family or neighbors will notice this?". Answers to this latter type of questions were recorded as figures between 0 and $100 \%$. In order to express them on the same scale as the Likert items, which is necessary for a correct scale analysis, we transformed them to a scale from 1 to 5 by dividing through 25 , then rounding down to an integer, and adding 1 . All items had satisfactory variance, for details we again refer to Monitorrapport (1998). The complete list of the - translated-items, showing to what $\mathrm{T}^{11}$ dimension they belong, is given in Appendix 1. The $\mathrm{T}_{3}$-dimension, acceptability of the concrete rules, and the $\mathrm{T}_{9}$-dimension, control selectivity, have not been included in the analysis, as the field work reports indicated that the relevant items were frequently misunderstood by respondents. The study from which we have taken the items covered much more data, but we only discuss those used in the present analysis.

The dependent variable, self-reported non-compliance, had been recorded twice, first using the locked box method, then by means of the randomized response technique. The exact text presented to the respondents to obtain a randomized response answer is given (translated from the original Dutch) in Appendix 2. 


\section{RESULTS}

\subsection{Condensing by Means of Scale Analysis, LRS-Case}

We have condensed the eleven dimensions of the $\mathrm{T}^{11}$ into seven groups: knowledge $\left(\mathrm{T}_{1}\right)$, costs and benefits $\left(\mathrm{T}_{2}\right)$, authority $\left(\mathrm{T}_{4}\right)$, social norms $\left(\mathrm{T}_{5}, \mathrm{~T}_{6}\right)$, control $\left(\mathrm{T}_{7}\right)$, detection $\left(\mathrm{T}_{8}\right)$ and sanctions $\left(\mathrm{T}_{10}, \mathrm{~T}_{11}\right)$. The first step in the analysis was to construct and test scales for the seven dimensions, by (linear) item analysis, computing Cronbach's $\alpha$ as a coefficient estimating the lowerbound of reliability, and removing items that have a low item-rest correlation with the scale. All scales are constructed such that a high score is expected to be associated with low compliance. For social science research purposes a reliability estimate higher than 0.7 is considered to be sufficient (Nunnally and Bernstein, 1994, pp. 264-5).

In a few cases we were unable to establish a scale consisting of all items as intended. A brief overview is given below.

In six out of seven cases we finished with a satisfactory scale, although we had to omit one item from the social norm scale, because its item-rest correlation was only 0.09 . Omitting it considerably improves the reliability of the remaining scale. Because that item lies rather at the heart of the concept of a social norm (the item reads: "Would your friends, family or neighbors approve or disapprove if you were to file the level of your income incorrectly?" with answers ranging from "strongly disapprove" to "strongly approve"), we decided to include it as a separately standing item in all subsequent analyses, under the name Social Norm-2.

Rather surprisingly, the two cost/benefit items displayed a low correlation of only 0.08 . We decided to drop one of them, as it happened to display a higher correlation with the knowledge items than with the remaining cost/benefit item that addressed the financial advantage of underreporting. This remaining item will be denoted further as Benefits of noncompliance.

Table I. Condensing $\mathrm{T}^{11}$ Dimensions, LRS

\begin{tabular}{lccccc}
\hline Scale & $\begin{array}{c}\text { Original } \\
\text { number } \\
\text { of items }\end{array}$ & $\begin{array}{c}\text { Cronbach's } \alpha \\
\text { before } \\
\text { rejection }\end{array}$ & $\begin{array}{c}\text { No. of } \\
\text { items } \\
\text { rejected }\end{array}$ & $\begin{array}{c}\text { Resulting } \\
\text { Cronbach's } \alpha\end{array}$ & $\begin{array}{c}\text { Final minimal } \\
\text { item rest } \\
\text { correlation }\end{array}$ \\
\hline Knowledge & 4 & 0.79 & 0 & 0.79 & 0.50 \\
Costs/benefits & 2 & 0.15 & 2 & - & - \\
Authority & 2 & 0.73 & 0 & 0.73 & 0.57 \\
Social Norm & 5 & 0.66 & 1 & 0.74 & 0.45 \\
Control & 4 & 0.81 & 0 & 0.81 & 0.52 \\
Detection & 4 & 0.80 & 0 & 0.81 & 0.51 \\
Sanctions & 6 & 0.73 & 0 & 0.73 & 0.17 \\
\hline
\end{tabular}


Table II. Condensing $\mathrm{T}^{11}$ Dimensions, LAC

\begin{tabular}{lccccc}
\hline Scale & $\begin{array}{c}\text { Original } \\
\text { number } \\
\text { of items }\end{array}$ & $\begin{array}{c}\text { Cronbach's } \alpha \\
\text { before } \\
\text { rejection }\end{array}$ & $\begin{array}{c}\text { No. of } \\
\text { items } \\
\text { rejected }\end{array}$ & $\begin{array}{c}\text { Resulting } \\
\text { Cronbach's } \alpha\end{array}$ & $\begin{array}{c}\text { Final minimal } \\
\text { item rest } \\
\text { correlation }\end{array}$ \\
\hline Knowledge & 3 & 0.51 & 0 & 0.51 & 0.27 \\
Costs/benefits & 3 & 0.41 & 1 & 0.60 & 0.43 \\
Authority & 2 & 0.81 & 0 & 0.81 & 0.68 \\
Social Norm & 5 & 0.60 & 1 & 0.65 & 0.29 \\
Control & 4 & 0.71 & 0 & 0.71 & 0.44 \\
Detection & 4 & 0.73 & 0 & 0.73 & 0.44 \\
Sanctions & 6 & 0.71 & 0 & 0.71 & 0.16 \\
\hline
\end{tabular}

\subsection{Condensing by Means of Scale Analysis, LAC-Case}

As in the LRS-case, the $\mathrm{T}^{11}$ dimensions were grouped into the same seven groups and scale analysis was carried out. (See Table II above.)

Three scales initially did not meet the Nunnally-Bernstein standard that the reliability should exceed 0.70 . However, omitting an item does not result in an increased reliability for the knowledge scale. As the knowledge scale performed well in the LRS case, we propose to retain it here for reasons of symmetry. The cost/benefit scale was also under-performing, as in the LRS case, but in this case we propose to retain a two item scale, which performs rather better $(\alpha=0.6)$ though still rather low. This is, henceforth, called Benefits of non-compliance.

Again, one of the social norm questions is not performing brilliantly. Its item-rest correlation is only 0.14 , and though omitting it does not raise $\alpha$ substantially, we decided, also to maintain symmetry with the LRS case, to isolate it and to continue with it as a separate variable in the analysis, called Social Norm-2. The remaining four items do not quite live up to the Nunnally-Bernstein standard ( $\alpha=0.65)$, but are retained as Social Norm-1.

\subsection{Compliance Levels}

We first give an overview of the levels of non-compliance reported for the two laws, both by the locked box question and by means of the randomized response (RR) method, using Eq. (1).

We observe a considerable difference between locked box and randomized report estimates for the same law. The non-compliance estimates under the randomized report method are twice as high as those obtained under the locked box method. A clear picture emerges when we cross-classify the answers on the locked box method with those on the randomized response method (corrected according to Eq. (1)). We present 
Table III. Compliance levels

\begin{tabular}{|c|c|c|c|c|}
\hline & \multicolumn{2}{|l|}{ LAC } & \multicolumn{2}{|l|}{ LRS } \\
\hline & Locked box & $\mathrm{RR}$ & Locked box & $\mathrm{RR}$ \\
\hline & \multicolumn{2}{|l|}{345} & \multicolumn{2}{|l|}{323} \\
\hline$\%$ "no answers", & $6 \%$ & $8 \%$ & $3 \%$ & $7 \%$ \\
\hline No. of valid cases & 325 & 317 & 314 & 299 \\
\hline$\%$ Non-compliance (w.r.t. valid cases) & $11 \%$ & $24 \%$ & $4 \%$ & $8 \%$ \\
\hline
\end{tabular}

here the results for the LAC case only, because in the case of the LRS, the locked box method displays 11 cases of admittance only, too few for cross tabulation. (See Table III above.)

Table IV shows that, from 300 individuals, 223 deny on both methods, 29 admit on both methods, but interestingly, there are 44 who admit in randomized response mode, but deny in the locked box mode, yet there are only 4 individuals who do the reverse. We have no evidence in the data that these 44 individuals are different in their transgressing behavior from the 29 individuals in the upper left cell. Our interpretation is that the randomized response method provides more valid estimates than the locked box method, and a reason for this may be that the perceived safety of the randomized response method is larger. We conclude that the locked box method is less trustworthy, considerably underestimating the true non-compliance level. For this reason, we shall carry on with the analyses using the randomized response method only.

Table IV. Cross Classification of Admittance in Locked Box and Randomized Response Methods, LAC Case

\begin{tabular}{cccr}
\hline & & \multicolumn{2}{c}{$\begin{array}{c}\text { Randomized response method, } \\
\text { corrected according to Eq. (1) }\end{array}$} \\
\cline { 3 - 4 } Estimated frequencies & $\begin{array}{c}\text { Admits } \\
\text { non-compliance }\end{array}$ & $\begin{array}{c}\text { Denies } \\
\text { non-compliance }\end{array}$ \\
\hline \multirow{2}{*}{ Locked box method } & Admits non-compliance & 29.25 & 3.75 \\
& Denies non-compliance & 44.25 & 222.75 \\
\hline
\end{tabular}




\subsection{Logistic Regression Results}

Using the method outlined above, we have estimated the regression coefficients in an adjusted univariate logistic regression of the randomized response self-reported non-compliance on the 8 condensed $\mathrm{T}^{11}$-scales (see Table V).

We observe that, within the group of spontaneous compliance factors, only one, viz. the benefits of non-compliance, has any explanatory power: the greater the perceived benefits, the more non-compliance we get. None of the others makes a significant contribution. We interpret this as follows: contrary to common belief about the LRS, the perceived complexity of the law has nothing to do with compliance. Education or information therefore cannot enhance compliance, nor does general respect for the law contribute either. Informal control also has no important contribution to make, probably because rent subsidy fraud is rather invisible to outsiders. On the other hand, all variates from the induced factors do contribute significantly to an explanation, in the sense that the more perceived probability of control, certainty of detection (conditional on control) and severity of sanction, the less non-compliance.

We reiterate the adjusted logistic regression in a multivariate way, since many $\mathrm{T}^{11}$ dimensions are correlated. We include only those variates as explanatory variables that display significant $b$-coefficients in Table V. This has been done to preclude convergence problems in the numerical optimization algorithms, as indicated above.

Table V. Adjusted Univariate Logistic Regression, LRS. Dependent Variable: Randomized Response Variable. Explanatory Variables: Condensed $\mathrm{T}^{11}$-scales

\begin{tabular}{lrrrc}
\hline Condensed $\mathrm{T}^{11}$-scale & $c$ & $\mathrm{~B}$ & $\mathrm{se}(b)$ & signif. \\
\hline Spontaneous scales & & & & \\
$\quad$ Knowledge & -2.38 & -0.01 & 0.13 & \\
Benefits of non-compliance & 0.19 & 0.68 & 0.35 & $\times$ \\
Authority & -1.37 & -0.18 & 0.26 & \\
Social Norm 1 & -1.52 & -0.11 & 0.12 & \\
$\quad$ Social Norm 2 & -2.89 & -0.22 & 0.34 & \\
Induced scales & & & & \\
Control & -0.59 & -0.17 & 0.09 & $\times$ \\
$\quad$ Detection & -0.84 & -0.13 & 0.06 & $\times$ \\
Sanctions & 0.39 & -0.15 & 0.07 & $\times$ \\
\hline
\end{tabular}

Note: Given are parameter estimates for intercept $c$ and unstandardized regression weight $b$, and standard errors of $b$. When |estimate/standard error $\mid>1.96$, the estimate departs significantly from zero (2-sided test). These are indicated with an " $x$ " in the column "signif.". 
Table VI. Adjusted Multivariate Logistic Regression, LRS. Dependent Variable: Randomized Response Variables. Explanatory Variables: Condensed $\mathrm{T}^{11}$-scales.

\begin{tabular}{|c|c|c|c|c|c|c|}
\hline \multirow{3}{*}{ Scales } & \multicolumn{6}{|c|}{ LRS } \\
\hline & \multicolumn{3}{|c|}{ Multi-variate* } & \multicolumn{3}{|c|}{ Uni-variate } \\
\hline & $b$ & $\mathrm{se}(b)$ & signif. & $b$ & $\operatorname{se}(b)$ & signif. \\
\hline Benefits & 0.94 & 0.36 & $x$ & 0.68 & 0.35 & $\mathrm{x}$ \\
\hline Control & -0.14 & 0.17 & & -0.17 & 0.09 & $\mathrm{x}$ \\
\hline Detection & 0.00 & 0.15 & & -0.13 & 0.06 & $\mathrm{x}$ \\
\hline Sanctions & 0.17 & 0.11 & & -0.15 & 0.07 & $\mathrm{x}$ \\
\hline
\end{tabular}

*The estimate of the constant term in the multi-variate case is: 5.98 Given are parameter estimates for unstandardized regression weight $b$, with standard errors of $b$. When lestimate/ standard error $\mid>1.96$, the estimate departs significantly from zero (2-sided test). These are indicated with an " $\times$ " in the column "signif". For comparison, uni-variate $b$-estimates from Table $\mathrm{V}$ are given as well.

It should be noted that the univariately significant contributions of the control, detection, and sanction dimensions lose their significance, benefits remaining the only factor that contributes to the explanation of compliance. (See Table VI.) This would seem to suggest that respondents did not score "benefits" without already taking into account that non-compliance may have its negative side, as a result of enforcement. If this suggestion holds true, it indicates the need to address the measurement problem of the benefit dimension somewhat more careful.

We now turn to the LAC. For this law, we observe that none of the induced scales displays any explanatory power. This means that farmers find the enforcement system no threat at all, if they are considering the use of forbidden chemicals. This finding should alert the agricultural inspectorate. The spontaneous factors, however, make a double contribution, through the expected benefits of non-compliance, which has a great contribution to make, and the second social norm, i.e., what other farmers would think or say if they knew a respondent was using prohibited chemicals. The perceived disapproval of other farmers certainly helps to prevent non-compliance. The knowledge factor has nothing to do with it: more information and advice on the law would not enhance compliance. (See Table VII below)

Table VIII shows the multivariate adjusted logistic regression for the LAC-case.

The contributions of the two explanatory variables remain almost exactly the same in the multivariate analysis. 
Table VII. Adjusted Univariate Logistic Regression, LAC. Dependent Variable: Randomized Response Variable. Explanatory Variables: Condensed $\mathrm{T}^{11}$-scales.

\begin{tabular}{lrrrc}
\hline Condensed $\mathrm{T}^{11}$-scale & $c$ & $b$ & $\operatorname{se}(b)$ & signif. \\
\hline Spontaneous scales & & & & \\
$\quad$ Knowledge & -0.08 & -0.11 & 0.09 & \\
$\quad$ Benefits of non-compliance & -1.98 & 0.47 & 0.13 & $\times$ \\
Authority & -0.44 & -0.14 & 0.10 & \\
Social Norm 1 & -1.04 & -0.01 & 0.06 & \\
$\quad$ Social Norm 2 & -2.34 & -0.44 & 0.20 & $\times$ \\
Induced scales & & & & \\
Control & -1.20 & -0.00 & 0.05 & \\
$\quad$ Detection & -1.50 & 0.03 & 0.05 & \\
Sanctions & -1.31 & 0.00 & 0.04 & \\
\hline
\end{tabular}

Note: Given are parameter estimates for intercept $c$ and unstandardized regression weight $b$, and standard errors of $b$. When |estimate/standard error $\mid>1.96$, the estimate departs significantly from zero (2-sided test). These are indicated with an " $x$ " in the column "signif".

Table VIII. Adjusted Multivariate Logistic Regression, LAC Dependent Variable: Randomized Response Variables. Explanatory Variables: Condensed $\mathrm{T}^{11}$-scales

\begin{tabular}{|c|c|c|c|c|c|c|}
\hline \multirow{3}{*}{ Scales } & \multicolumn{6}{|c|}{ LAC } \\
\hline & \multicolumn{3}{|c|}{ Multi-variate* } & \multicolumn{3}{|c|}{ Uni-variate } \\
\hline & $b$ & $\operatorname{se}(b)$ & signif. & $b$ & $\operatorname{se}(b)$ & signif. \\
\hline Benefits & 0.49 & 0.14 & $x$ & 0.47 & 0.13 & $x$ \\
\hline Social Norm 2 & -0.47 & 0.23 & $x$ & -0.44 & 0.20 & $x$ \\
\hline
\end{tabular}

*Estimate of constant in multi-variate case: -0.84 .

Note: Given are parameter estimates for intercept $c$ and unstandardized regression weight $b$, with standard errors of $b$. When |estimate/standard error $\mid>1.96$, the estimate departs significantly from zero (2-sided test). These are indicated with an asterisk. For comparison uni-variate $b$-estimates from Table VII are given as well.

\subsection{EFFECT SIZE}

As $b$-values are rather difficult to interpret, we compute the effect size of the significant scales, by comparing the estimated probability of noncompliance when the explanatory variable has a value plus or minus one standard deviation from its mean. The difference between those two estimates is called the effect size for the relevant explanatory factor.

Table IX shows that, in terms of percentage non-compliers, the contribution of all variables reaching significance in the adjusted logistic regression analyses is indeed considerable. In the LRS case, enhancing the perception of a stronger control mechanism (control, detection, sanctions) 
Table IX. Effect Size of Explanatory $\mathrm{T}^{11}$ Dimensions. Estimated Probabilities of Noncompliance (EPNC) when Explanatory Variable is Plus or Minus One (Sample) Standard Deviation from its (Sample) Mean. Effect Size (ES) is the Difference between the Level Estimates at + or - One Standard Deviation.

\begin{tabular}{|c|c|c|c|c|c|c|}
\hline \multirow[b]{3}{*}{ Scales } & \multicolumn{3}{|c|}{ LRS } & \multicolumn{3}{|c|}{ LAC } \\
\hline & \multicolumn{3}{|c|}{ EPNC total group: $8 \%$} & \multicolumn{3}{|c|}{ EPNC total group: $24 \%$} \\
\hline & $\begin{array}{l}\text { EPNC at } \\
-1 \text { st.dev. }\end{array}$ & $\begin{array}{l}\text { EPNC at } \\
+1 \text { st.dev. }\end{array}$ & $\begin{array}{c}\text { Effect size } \\
\text { ES }\end{array}$ & $\begin{array}{l}\text { EPNC at } \\
-1 \text { st.dev. }\end{array}$ & $\begin{array}{l}\text { EPNC at } \\
+1 \text { st.dev. }\end{array}$ & $\begin{array}{c}\text { Effect size } \\
\text { ES }\end{array}$ \\
\hline $\begin{array}{l}\text { Benefits } \\
\text { Social Norm } 2\end{array}$ & $3 \%$ & $12 \%$ & $9 \%$ & $\begin{array}{r}8 \% \\
15 \%\end{array}$ & $\begin{array}{l}42 \% \\
33 \%\end{array}$ & $\begin{array}{l}34 \% \\
18 \%\end{array}$ \\
\hline $\begin{array}{l}\text { Control } \\
\text { Detection } \\
\text { Sanctions }\end{array}$ & $\begin{array}{l}4 \% \\
5 \% \\
4 \%\end{array}$ & $\begin{array}{l}17 \% \\
16 \% \\
19 \%\end{array}$ & $\begin{array}{l}13 \% \\
11 \% \\
15 \%\end{array}$ & & & \\
\hline
\end{tabular}

Note: We include only explanatory variables having significant regression weights in Table $\mathrm{V}$ or Table VII. Empty cells indicate that the factor concerned did not reach significance for that law. would result in a considerably higher level of compliance, while reducing the perceived benefits of non-compliance would also help substantially. In the LAC case, the effects are even more dramatic. Reducing the benefits of noncompliance, as well as increasing the social stigma attached to transgressing the rules, would have a very large impact on non-compliance.

\section{DISCUSSION}

Within the Becker-Fishbein-Ajzen style of rational choice modeling of regulatory non-compliance, we have used an inventory of the relevant factors, using the Table-of-Eleven as a heuristic. Distinguishing between spontaneous compliance factors (relevant to the inclination to transgress a rule) on the one hand, and induced compliance factors (addressing the enforcement of the law) on the other, we were able to show the relevance of various factors. Rather in line with a simple version of a Beckerian rational choice framework, we have demonstrated that the perceived benefits of noncompliance are indeed a major factor promoting rule transgression in two completely different regulatory laws. On the other hand, the other Beckerian favorites, the perceived expected costs of non-compliance in terms of punishment, came out as important in only one of these cases. Perceived social norms, as indicators of non-monetary costs of non-compliance, played a role in one of the cases studied.

We propose to evaluate this state of affairs as follows:

- a rational choice framework for explaining regulatory compliance is useful; 
- the table-of-eleven scheme for sorting out different influences within a rational choice frame turns out to be useful;

- but which particular determinants of non-compliance are important for a given law is law-dependent, which means that the findings are rather context dependent;

- important determinants can be identified only by correlating them with a valid non-compliance measure

- for which a randomized response operationalization was shown to be feasible

- by using an adapted logistic regression method.

It should be clear that it is no easy task to influence the factors that we have shown to be effective. First of all we should be aware that all our results concern perceived $\mathrm{T}^{11}$ factors, and altering objective levels is by no means identical to altering perceived levels. Also changing objective factors may be difficult in itself. For example, benefits are, in general, given in the context and situation of a particular law: the fact that using prohibited chemicals is effective for a crop is, of course, a fact of agricultural life that cannot be altered, except by reclassifying the substance as legally permitted. However, other factors may in principle be altered, such as social stigma. The control factors in the LRS case can also be altered, either by actually increasing frequency of control, or by making people more aware of the chances of being controlled, detected and sanctioned.

The fact that we have shown that several factors have no effect in our samples, is no absolute proof that it is useless to manipulate them. We have demonstrated that within the range in which the respondents' perception varies, a considerable change would have no significant effect. It is conceivable that a change on a much larger scale might be effective, but such a change would need to be so great that under present circumstances it ceases to be imaginable.

We may wonder why the two laws evaluated in this study in fact display such a different compliance pattern. Why are enforcement factors relevant for the LRS, but not so for the LAC? It is possible that this is the case because non-compliant farmers have much more experience of the ineffectiveness of enforcement than do LRS non-compliers, and that they are adept at recognizing enforcement activities. If he uses prohibited chemicals repeatedly and knowingly, the perpetrator will know from experience that enforcement by the AID is a weak threat. For LRS frauds, non-compliance perhaps has a more diffuse character, as perpetrators only occasionally file unfamiliar forms, and the fraud in fact occurs at an administrative level. What those vague and not wholly understood administrative enforcers actually do is perhaps unclear, and therefore the more of a threat to many LRS beneficiaries? In fact, we suggest here that 
different perceptions of what is going on in the enforcement of both law is responsible for the different effect of enforcement factors.

With reference to social norms, we would venture a suggestion: farmers using forbidden substances know that they achieve a real improvement in their market position vis-à-vis compliant farmers, their competitors. They register the social norm that those competitors would condemn their actions. Farmers aware of this (having high scores on social norm-2) may well respond to it, thus constraining their non-compliance. On the other hand, the LRS case is one in which non-compliance is at the expense of the common budget, possibly identified as "the government", where the position of any other rent subsidy receivers is only marginally affected, if at all.

From a methodological point of view, we believe this study to be a contribution to the empirical evidence that direct survey self-reports on noncompliance are inadequate. Comparing direct self-reports (using the locked box method) with randomized responses, we observe for both laws that estimates of the prevalence of non-compliance almost doubled when the randomized response method was used. 
The following questions from the Monitorrapport (1998) are used in the LRS case.

Original/condensed

The question reads in translation: (original in Dutch)

$\mathrm{T}^{11}$ dimension

1. How much do you know about the rules concerning the level of the household income and the right to individual rent subsidy?

$\mathrm{T}_{1} /$ Knowledge

2. How clear do you find the rules about the level of the household income and the right to individual rent subsidy?

3. How complex do you find the rules about the level of the household income and the right to individual rent subsidy?

4. How complex do you find the explanation accompanying the form you have complete to obtain individual rent subsidy?

5. How much do you think your benefit could be if you filed your income falsely?

6. If you wished to declare your income falsely, how difficult would it be to do so?

7. Do you agree with the statement: "one should always obey the government?"

8. Do you agree with the statement: "one should always obey the law?"

9. If you wished to declare your income falsely, what is the chance that your friends, family or neighbors would notice this?

$\mathrm{T}_{1} /$ Knowledge

$\mathrm{T}_{1} /$ Knowledge

$\mathrm{T}_{1} /$ Knowledge

$\mathrm{T}_{2} /$ Benefits

$\mathrm{T}_{2} /$ rejected

$\mathrm{T}_{4} /$ Authority

$\mathrm{T}_{4} /$ Authority

10. Is this chance such that you would or would not take it into consideration when declaring your income?

$\mathrm{T}_{5} /$ Social Norm 1

$\mathrm{T}_{5} /$ Social Norm 1

1. Would your friends, family or neighbors approve or disapprove if you declared your income falsely?

$\mathrm{T}_{5} /$ Social Norm 2

12. Suppose your friends, family or neighbors were to become aware that you had declared your income falsely. What do you think is the probability of someone around you reporting you to the authorities?

13. Is this probability such that you would or would not take it into consideration when declaring your income? 
The following questions from the Monitorrapport (1998) are used in the LRS case.

Original/condensed The question reads in translation: (original in Dutch)

14. What do you think is the chance that the authorities would check your declaration on the height of your income?

$\mathrm{T}_{7} /$ Control

15. Is this chance such that you would or would not take it into consideration when declaring your income?

$\mathrm{T}_{7} /$ Control

16. What do you think is the chance that the authorities would visit your home to check your declared income?

$\mathrm{T}_{7} /$ Control

17. Is this chance such that you would or would not take it into consideration when declaring your income?

$\mathrm{T}_{7} /$ Control

18. Suppose you had made a false declaration. If authorities checked your declaration, how great do you estimate the probability that they would actually detect your offense?

$\mathrm{T}_{8} /$ Detection

19. Is this probability such that you would or would not take it into consideration when declaring your income?

20. Suppose you had given a false declaration and the authorities visited your home to check the facts. How do you estimate the chance that they would actually detect such an offense?

21. Is this chance such that you would or would not take it into consideration when declaring your income?

22. What do you estimate is the probability of being penalized in one way or another, should the authorities discover that you had falsely declared your income?

23. Is this probability such that you would or would not take it into consideration when declaring your income?

24. How do you rate the severity of the usual penalty for false declarations of income?

25. Is the severity of the penalty such that you would or would not take it into consideration when declaring your income?

26. How severely would your good name be affected if it were to become known that you had falsely declared your income?

$\mathrm{T}_{8} /$ Detection

$\mathrm{T}_{8} /$ Detection

$\mathrm{T}_{8} /$ Detection

$\mathrm{T}_{10} /$ Sanction

$\mathrm{T}_{10} /$ Sanction

$\mathrm{T}_{11} /$ Sanction

$\mathrm{T}_{11} /$ Sanction

$\mathrm{T}_{11} /$ Sanction 
The following questions from the Monitorrapport (1998) are used in the LRS case.

Original/condensed

The question reads in translation: (original in Dutch)

$\mathrm{T}^{11}$ dimension

27. Is the severity such that you would or would not take it into consideration when declaring your income?

$\mathrm{T}_{11} /$ Sanction

The following questions from the Monitorrapport (1998) are used in the LAC case. The question reads in translation: (original in Dutch)

1. How much do you know of the rules concerning the agricultural chemicals you are allowed to use?

2. How clear do you find the rules concerning the agricultural chemicals you are allowed to use?

3. How complex do you find the rules concerning the agricultural chemicals you are allowed to use?

4. How great do you think the financial and economic benefits would be if you were to break the rules about the agricultural chemicals you are allowed to use?

5. Suppose you wanted to buy proscribed agricultural chemicals, how difficult would it be to obtain them?

6. How great do you judge the disadvantages (costs and efforts) of observing the rules on the agricultural chemicals you are allowed to use?

7. Do you agree with the statement: "one should always obey the government?"

8. Do you agree with the statement: "one should always obey the law?"

9. Suppose you wanted to disobey the rules on agricultural chemicals you are allowed to use, how great is the chance that someone (colleagues, neighbors, competitors) would notice this?

$\mathrm{T}_{1} /$ Knowledge

$\mathrm{T}_{1} /$ Knowledge

$\mathrm{T}_{1} /$ Knowledge

$\mathrm{T}_{2} /$ Benefits

$\mathrm{T}_{2} /$ Benefits

$\mathrm{T}_{2} /$ rejected

$\mathrm{T}_{4} /$ Authority

$\mathrm{T}_{4} /$ Authority

$\mathrm{T}_{5} /$ Social Norm 1

10. Is this chance such that you would or would not take it into consideration when deciding whether to obey the rules on the agricultural chemicals you are allowed to use?

$\mathrm{T}_{5} /$ Social Norm 1

11. Would people around you (colleagues, neighbours, competitors) approve or disapprove if you were to break the rules on the agricultural chemicals you are allowed to use?

$\mathrm{T}_{5} /$ Social Norm 2 
The following questions from the Monitorrapport (1998) are used in the LAC case. The question reads in translation: (original in Dutch)

12. Suppose someone were to become aware that you had broken the rules on the agricultural chemicals you are allowed to use, how great do you estimate the probability that he would report you to the authorities?

$\mathrm{T}_{6} /$ Social Norm 1

13. Is this probability such that you would or would not take it into consideration when deciding whether to obey the rules on the agricultural chemicals you are allowed to use?

$\mathrm{T}_{6} /$ Social Norm 1

14. How great do you estimate the chance that the authorities would visit your company to check compliance with the rules on the agricultural chemicals you are allowed to use?

15. Is this chance such that you would or would not take it into consideration when deciding whether to obey the rules on the agricultural chemicals you are allowed to use?

$\mathrm{T}_{7} /$ Control

$\mathrm{T}_{7} /$ Control

6. How great do you estimate the probability of the authorities checking your business accounts for compliance with the rules on agricultural chemicals you are allowed to use?

$\mathrm{T}_{7} /$ Control

17. Is this probability such that you would or would not take it into consideration when deciding whether to obey the rules on the agricultural chemicals you are allowed to use?

$\mathrm{T}_{7} /$ Control

8. Suppose you had broken the rules on the agricultural chemicals you are allowed to use, and the authorities checked your business administration, how great do you estimate the probability that they would actually detect your offense?

$\mathrm{T}_{8} /$ Detection

19. Is this probability such that you would or would not take it into consideration when deciding whether to obey the rules on the agricultural chemicals you are allowed to use?

$\mathrm{T}_{8} /$ Detection

20. Suppose you had broken the rules on the agricultural chemicals you are allowed to use, and the authorities visited your company for inspection, how great do you estimate the chance that they would actually detect your offense?

$\mathrm{T}_{8} /$ Detection

21. Is this chance such that you would or would not take it into consideration when deciding whether to obey the rules on the agricultural chemicals you are allowed to use?

$\mathrm{T}_{8} /$ Detection 
The following questions from the Monitorrapport (1998) are used in the LAC case. The question reads in translation: (original in Dutch)

22. How great do you estimate the chance that you would be penalized in one way or another, should the authorities discover that you had ignored the rules on the agricultural chemicals you are allowed to use?

$\mathrm{T}_{10} /$ Sanction

23. Is this chance such that you would or would not take it into consideration when deciding whether to obey the rules on the agricultural chemicals you are allowed to use?

$\mathrm{T}_{10} /$ Sanction

24. How severe do you think are the usual penalties are for ignoring the rules on the agricultural chemicals you are allowed to use?

25. Is this severity such that you would or would not take it into consideration when deciding whether to obey the rules on the agricultural chemicals you are allowed to use?

$\mathrm{T}_{11} /$ Sanction

26. How severely would your good name be affected if it were to become known that you had ignored the rules on the agricultural chemicals you are allowed to use?

$\mathrm{T}_{11} /$ Sanction

7. Is the severity that you just mentioned such that you would or would not take it into

consideration when deciding whether to obey the rules on the agricultural chemicals you are allowed

to use?

$\mathrm{T}_{11} /$ Sanction

$\mathrm{T}_{11} /$ Sanction 


\section{APPENDIX 2. Procedure Randomized Response Items}

For the law on individual rent subsidy, after questions about the respondents' background characteristics, his/her financial situation, the items of $\mathrm{T}^{11}$, and items about reasons for compliance or non-compliance, the randomized response question was asked. The interviewer instruction was phrased as follows:

"It is natural that not everybody is willing to say whether he/she has ever trespassed the rules for individual rent subsidy. We will now use an often used method that allows you to answer honestly without running any risk. The reason is that with this method we cannot assess which question is answered by whom. In a few minutes you will be asked to throw dice.

If you throw a 1 or 2, I will ask you to answer the following question: 'Is your mothers birthday between January 1 and June 30?' If you throw a 3, 4, 5 or 6, we ask you to answer a different question, namely: 'Did you provide, in the past 12 months, incorrect information about your income for the individual rent subsidy?' You only have to answer 'yes' or 'no' to the question asked after throwing the die. I shall not look at the outcome of the throw. So I can never know which question you answer.' (INTERVIEWER: show card with dice procedure)."

For the law on agricultural chemicals, the same procedure was used, where at the relevant places the following phrases were inserted: "... whether your firm has ever trespassed the rules for agricultural chemicals..."

\section{REFERENCES}

Andreoni, J., Erard, B., and Feinstein, J. (1998). Tax Compliance. J. Econ. Lit. 36: 818-860. Becker, G. S. (1968). Crime and punishment: An economic approach. J. Polit. Econ. 76: 169-217. Casey, J. T., and Scholz, J. T. (1991). Beyond deterrence; Behavioral decision theory and tax compliance. Law Soc. Rev. 25: 821-843.

Chaudhuri, A., and Mukerjee, R. (1988). Randomized Response: Theory and Techniques, Dekker, New York.

De eerste stap [The first step] (1994). Inspectie voor de Rechtshandhaving, Den Haag.

Elffers, H. (1991). Income Tax Evasion; Theory and Measurement, Kluwer, Deventer.

Elffers, H. (1999). Tax Evasion. In Earl, P. E. and Kemp, S. (eds.), The Elgar Companion to Consumer Research and Economic Psychology, Edward Elgar, Cheltenham, pp. 556-560.

Elffers, H. (2000). Over het nut van survey-onderzoek met de Tafel van Elf [On the use of survey research using the Table of Eleven]. In: Van Reenen, P. (ed.), De Tafel van Elf, Sdu Uitgevers, Den Haag, pp. 79-85.

Elffers, H., and Hessing, D. J. (2001). Individual differences and rational deterrence. In Scott, A. J. (ed.) Environment and Wellbeing. Proceedings of the XXVIth Annual Conference of the 
International Association for Research in Economic Psychology. University of Bath Press, Bath, pp. 62-66.

Elffers, H., and Ruimschotel, D. (1997). The Table of Eleven $\left(T_{11}\right)$ as a new content oriented paradigm for evaluation research. Paper presented at the 1997 Stockholm Conference of the European Evaluation Society, Sanders Instituut EUR, Rotterdam.

Fishbein, M., and Ajzen, I. (1975). Belief, Attitude, Intention and Behavior, Addison Wesley, Reading, Mass.

Fox, J. A., and Tracey, P. E. (1986). Randomized Response. A Method for Sensitive Surveys. Quantitative Applications in the Social Sciences, Sage, Beverley Hills.

Grasmick, H. G., and Bursik, R. J., Jr. (1990). Conscience, significant others, and rational choice: Extending the deterrence model. Law Soc. Rev. 24: 837-861.

Hatcher, A., Thebaud, O., and Jaffry, S. (2000). An economic analysis of compliance with fishery regulations. In Van Vugt, M., Snyder, M., Tyler T. R., and Biel, A. (eds.), Cooperation in Modern Society. Promoting the Welfare of Communities, States and Organizations. Routledge, London, pp. 83-101.

Hessing, D. J., Weigel, R. H., and Elffers, H. (1988). Exploring the limits of self-reports and reasoned action: An investigation of the psychology of tax evasion behavior. J. Person. Soc. Psychol. 54: 405-413.

Heyes, A. (2000). Implementing Environmental Regulation: Enforcement and Compliance. J. Regul. Econ. 17: 107-129.

Junger-Tas, J., and Haen Marshall, I. (1999). The self-report methodology in crime research. In Tonry, M. (ed.). Crime and Justice: A Review of Research, Vol 25, University of Chicago Press, Chicago, pp. 291-367.

Klepper, S., and Nagin, D. (1989). The criminal deterrence literature: Implications for research on taxpayer compliance. In Roth, J. A., and Scholz, J. T. (eds.) Taxpayer Compliance, Vol. 2: Social Science Perspectives. University of Pennsylvania Press, Philadelphia, pp. 126-155.

Landsheer, J. A., Van der Heijden, P. G. M., and Van Gils, G. (1999). Trust and understanding, two psychological aspects of randomized response. A study of a method for improving the estimate of social security fraud. Qual. Quant. 33: 1-12.

Lensvelt, G. J. L. M., Hox, J. J., and Van der Heijden, P. G. M. (2002). Meta-analysis of randomized response research: 35 years of validation (submitted).

Maddala, G. S. (1983). Limited Dependent and Qualitative Variables in Econometrics. Cambridge University Press, New York.

Makkai, T., and Braithwaite, J. (1991). Criminological theories and regulatory compliance. Criminology 29: 191-217.

McCrohan, K. F. (1982). The use of survey research to estimate trends in non-compliance with federal income taxes. J. Econ. Psychol. 2: 231-240.

Monitorrapport (1998). Monitoring van beleidsinstrumentele wetgeving. [Monitoring regulatory laws]. Inspectie voor de Rechtshandhaving, Den Haag.

Nagin, D. S., and Paternoster, R. (1993). Enduring individual differences and rational choice theories of crime. Law Soc. Rev. 27: 467-496.

Nagin, D. S., and Pogarsky, G. (2001). Integrating celerity, impulsivity, and extralegal sanction threats into a model of general deterrence: theory and evidence. Criminology 39: 865-892.

Nunnally, J. C., and Bernstein, I. H. (1994). Psychometric Theory (3rd. ed.), McGraw-Hill, New York.

OECD (1999). The state of regulatory compliance: issues, trends and challenges. Document PUMA/REG(99)3, prepared for the Meeting of the Regulatory Management and Reform Group, Public Management Committee, at the OECD Headquarters, June 28-29, 1999. 
Parker, D., Manstead, A. S. R., Stradling, S. G., Reason, J. T., and Baxter, J. S. (1992). Intention to commit driving violations: an application of the theory of planned behaviour. J. Appl. Psychol. 77: 94-101.

Paternoster, R., and Simpson, S. (1996). Sanction threats and appeals to morality: Testing a rational choice model of corporate crime. Law Soc. Rev. 30: 549-583.

Roth, J. A., and Scholz, J. T. (eds.), (1989). Taxpayer Compliance, Vol. 2: Social Science Perspectives. University of Pennsylvania Press, Philadelphia.

Ruimschotel, D., Van Reenen, P., and Klaasen, H. M. (1995). Tussen norm en feit. [Between standard and fact]. Beleidsanalyse 2: 15-23.

Ruimschotel, D., Van Reenen, P., and Klaasen, H. M. (1996). De Tafel-van-Elf. [The Table-ofEleven]. Beleidsanalyse 3: 4-13.

Scheers, N. J., and Dayton, C. M. (1988). Covariate randomized response models. J. Am. Stat. Assoc. 83: 969-974.

Slemrod, J. (ed.), (1992), Why People Pay Taxes: Tax Compliance and Enforcement. University of Michigan Press, Ann Arbor.

Statistics Netherlands (2000). Statistisch Jaarboek 2000. Centraal Bureau voor de Statistiek, Heerlen/Voorburg.

Umesh, U. N., and Peterson, R. A. (1991). A critical evaluation of the randomized response method. Sociol. Methods Res. 20: 104-138.

Van der Heijden, P. G. M., Van Gils, G., Bouts, J., and Hox, J. (2000). A comparison of randomized response, CASAQ, and direct questioning; eliciting sensitive information in the context of welfare and unemployment benefit. Sociol. Methods Res. 28: 505-537.

Van Reenen, P. (ed.), (2000). De Tafel van Elf [The Table of Eleven]. Sdu Uitgevers, Den Haag.

Vaughan, D. (1998). Rational choice, situated action and the social control of organizations. Law Soc. Rev. 32: 23-61.

Warner, S. L. (1965). Randomized response: A survey technique for eliminating evasive answer bias. J. Am. Stat. Assoc. 60: 63-69. 